\title{
Ambiguity, ambivalence and absence in Zero Dark Thirty
}

Book or Report Section

Accepted Version

Purse, L. (2017) Ambiguity, ambivalence and absence in Zero Dark Thirty. In: Purse, L. and Hellmich, C. (eds.) Disappearing War Interdisciplinary Perspectives on Cinema and Erasure in the Post-9/11 World. Edinburgh University Press, Edinburgh, pp. 131-148. ISBN 9781474416566 Available at https://centaur.reading.ac.uk/71580/

It is advisable to refer to the publisher's version if you intend to cite from the work. See Guidance on citing.

Publisher: Edinburgh University Press

All outputs in CentAUR are protected by Intellectual Property Rights law, including copyright law. Copyright and IPR is retained by the creators or other copyright holders. Terms and conditions for use of this material are defined in the End User Agreement.

\section{www.reading.ac.uk/centaur}

\section{CentAUR}

Central Archive at the University of Reading 
Reading's research outputs online 


\section{Chapter 8}

\section{Ambiguity, Ambivalence and Absence in Zero Dark Thirty}

Lisa Purse

Zero Dark Thirty, Kathryn Bigelow's 2013 film about the ten year hunt for Osama bin Laden, has provoked competing accusations: that it is either anti-war or pro-war, anti-torture or pro-torture, and left wing or right wing in its political convictions. The heat of the assertions on either side of the debate (Naomi Wolf (2013) famously accused Bigelow of being ‘torture's handmaiden') illustrates the extent to which the film's subject matter — the post-9/11 counter-terrorism strategies deployed by the US Military and government agencies - itself continues to provoke vociferous political and cultural discussion. Not for the first (or last) time in American cinema history, a film becomes the site at which a nationally felt ambivalence — in this case, about US actions carried out in the name of the so-called 'war on terror' - is explored. Zero Dark Thirty has caused controversy not only because of its subject matter, but because of its ambiguity. The debates around the film have focused most intently on key elements of what is presented on-screen: the scenes of torture, the character of Maya (played by Jessica Chastain), and the killing of bin Laden. These have provoked strikingly contrasting interpretations, drawn from the same filmmaking decisions, and the same screen details. Thus Zero Dark Thirty has become what Frank Tomasulo once, in relation to a different war film, called a 'national Rorschach test' (Tomasulo 1990: 147). ${ }^{1}$ In this essay I want to unpick these ambiguities, to consider if Zero Dark Thirty gives voice to or counters a felt ambivalence about the war on terror, by examining what has sometimes slipped from view in the heated discussion of its scenes of torture and killing. That is, what absences might the compelling presences of Zero Dark Thirty obscure?

\section{Ambivalence and presence: locating ambiguity}

The film's moments of ambiguity — moments whose intended import can be interpreted in more than one way - are numerous, and I will examine some of these in what follows. Such a preponderance of ambiguity has the effect of producing political ambivalence at the structural level: that is, the film itself literally becomes a container for contradictory ideas and interpretations, allowing spectators who 
hold contrasting views to each see their convictions reflected in the text itself. Where felt ambivalence generally describes an individual or group's misgivings about a subject, structural ambivalence is simply the state of containing or permitting more than one viewpoint or interpretation at once. Structural ambivalence is often designed into American films that wish to address controversial subject matter without alienating parts of their audience, a strategy that, as Richard Maltby points out, 'displaces responsibility for the interpretation of a movie's content onto its audience' so that studios themselves are not accused of holding partisan political views (2003: 275; see also Tomasulo 1990: 147). One of the questions that Zero Dark Thirty prompts is how far one might perceive a felt ambivalence in the film's presentation of its subject, in addition to the structural ambivalence that is designed in.

The presence that seems most compelling for reviewers and commentators is that of Maya, the composite CIA agent who succeeds, in the film, in finding bin Laden. First encountered in the opening torture scenes, and positioned as participant in or behind-the-scenes instigator of almost every scene that follows, Maya is the central protagonist through which the spectator accesses the events the film depicts, and it is her persistence in the face of sceptical colleagues and superiors that is shown to win out in the hunt for bin Laden. Maya is herself a kind of Rorschach test, because her impassive demeanour is the embodiment of ambiguity, prompting a variety of interpretations of the character's motivations, psychological state(s) and emotional arc that serve contrasting readings of the wider movie. Two key moments are repeatedly cited in the attempt to 'read' Maya: her reaction to the torture of Ammar (Reda Kateb), an al Qaeda money man implicated in the financing of the 9/11 attacks, which is spread across three sequences in the first third of the movie; and the film's final shot, in which, after the culmination of the operation to locate and kill bin Laden, Maya sits silently in an empty aircraft and cries.

Significantly located at the beginning and end of the character's narrative arc in the film, these moments have generated confident assertions of Maya's emotional and intellectual responses from some quarters. For example, for Nick James, the final close-up of Maya in the aircraft shows she is 
undergoing the realisation 'that shooting bin Laden has achieved nothing much' (2013: 9); for Michael Boughn, she is experiencing the 'recognition of the irreparable wound the war has inflicted on the nation's soul' (2013: 26). Yet in fact the performance and framing of the scene resists clarification. Maya has boarded the plane, declining to enter into a conversation with the pilot. His practical question, 'Where do you want to go?' prompts a further silence. Maya starts to breathe more quickly, her brow wrinkling as her eyes fill with tears. Permitting herself to cry, she closes her eyes, then opens them, looking off screen left and right and then forward again as the tears pass (see figure 1). There are no words to clarify why she is crying, and no strong facial indicators of a particular emotion taking hold above others. Instead, multiple possibilities emerge: Agniezska Piotrowska's summation of Maya's state of mind at this moment, as 'reflective, tired, tearful but defiant' (2014: 154), seems most accurate precisely because it lists all of the emotions that are possibilities based on the performance. Ambiguity in the performance is matched by a narrative framing that also withholds: Maya is in a state of suspension, between question and answer, one mission and another, one direction and another, past and future, a suspension that does not resolve before the credits roll (see Burgoyne 2014: 197). ${ }^{2}$

\section{[insert figure 1 around here]}

Commentators' readings of Maya's reactions in the film's torture scenes evidence a similar pattern of confident interpretation based on ambiguous performance cues. These scenes are perhaps the most controversial presence in Zero Dark Thirty. Inaugurating and located within the chain of events that will lead to bin Laden's discovery and death, and viewed 'with the benefit of hindsight' that shows that the 'intelligence is accurate,' the torture scenes accrue, for some commentators, an undeserved and troubling legitimacy, or enact a problematic normalisation of so-called 'enhanced interrogation techniques' (Westwell 2013: 87, see also Maas 2012, Wolf 2013, Zizek 2013). In the torture scenes Maya watches, and eventually assists, as Ammar is subjected to hooding, beating, waterboarding, sound torture, sleep deprivation, food deprivation, sexual humiliation, light deprivation, is forced to wear a dog collar, and is confined to a box. Variety's Peter Debruge characterises Maya's body language in the torture scenes as child-like, and uses this as a basis for a straightforward assertion that 
Maya is 'clearly uncomfortable with the waterboarding and sexual humiliation that were common practice in the morally hazy rendition era' (2012: para 5, emphasis added). Michael Boughn offers a similarly confident summation of her state of mind: 'Young, naive, idealistic and female, she is compelled to prove herself in what is clearly a challenge to her moral sense' (2013: 24, emphasis added). The film offers some narrative information to contextualise Boughn and Debruge's characterisation of Maya as young and inexperienced but 'compelled to prove herself': Maya has just arrived, and wears inappropriate clothes to the interrogation; her resolve is indicated by her refusal of a coffee break mid-interrogation; she didn't ask for the transfer to Pakistan but Washington deems her a 'killer' CIA agent. But there is little narrative or dialogue indication that she is morally challenged.

Like in the final shot of the film, the performance cues that Debruge and Boughn are attempting to read are marked by an absence of thick emotional information. As Maya, Chastain at first looks down and away from Ammar as he is tortured, but later she directs her gaze more persistently at the spectacle of torture before her. Two traditionally self-comforting gestures (arms folded across the body as Ammar is water-boarded, hand massaging wrist as he is forcibly disrobed) convey the possibility of a felt discomfort, one that seems to be confirmed by an occasional swallowing or momentarily clenched jaw. Yet the absence of more communicative facial expressions or pointedly directed looks makes it difficult to locate the source of and motivation for Maya's discomfort; can one be confident, with Boughn, that this is a moral discomfort, or could it be, as Shohini Chaudhuri suggests, a baser revulsion towards a dehumanised Ammar (2014: 30)? ${ }^{3}$ Boughn's and Debruge's takes on Maya's feelings in the torture sequences exceed the performance cues presented by Chastain, betraying not just the commentators' own need to 'read' Maya as a psychologically rounded character, but their impulse to 'read' Chastain's performance in a manner that reflects their view of the wider film: in their cases, that Zero Dark Thirty's portrayal of torture is responsible rather than legitimising.

Across the film, Maya — and Chastain — are studiously impassive in ways that exceed narrative requirements. A certain steeliness of demeanour might be required in her professional, male- 
dominated, environment, for example, but Maya is equally inscrutable in private moments (watching television, eating alone). Her dialogue, too, is obfuscatory about the emotional dimensions of her experience: she only speaks about the mission. As if to underscore this inscrutability, the film occasionally obscures Maya's face behind light-suffused car windows, or toilet cubicle screens; more frequently it holds Maya's inexpressive face in close-up, as if, if one looked for long enough, she would reveal a clarifying emotional response. There is, then, a Kuleshovian structuring absence at the heart of Maya's characterisation. ${ }^{4}$ Manohla Dargis claims that Maya's 'vacant face' provides a platform for the spectator's productive questioning of the events and actions the film depicts, an embodiment of the film's progressive credentials: 'it is an article of faith,' she argues, 'that viewers are capable of filling in the blanks, managing narrative complexity and confronting their complicity' (2012: para 2, 6). Yet does this automatically follow? As we have seen, Boughn's and Debruge's readings emerge more from their own convictions, than from the evidence of the performance itself, implying that the absence at the heart of Chastain's performance does not necessarily move the spectator towards the wider contemplation or questioning of geopolitical realities that Dargis imagines. Indeed, Susan Carruthers suggests that instead it is Maya around which any questioning clusters: 'To the extent that Zero Dark Thirty instigates curiosity,' she observes, 'it's largely directed toward conjuring an inner life' for Maya, at the expense of, for example, questions about the efficacy and legality of torture, or the ethical and legal dimensions of extra-judicial killing (2013: 52). Herein lies the risk inherent in the film's most visible presence/absence — Maya's face — and the compelling mystery of the unclarified inner life it emblematises: that it directs the spectator away from other kinds of questions and other kinds of absences.

\section{Narrative patterns and perspectives: locating erasure}

Kathryn Bigelow has explained that the goal of Zero Dark Thirty was 'to make a modern, rigorous film about counter-terrorism' (Bigelow 2013: para 1), and she argues that this is a film that expresses a felt ambivalence about those counter-terrorist activities: 'I think that it's a deeply moral movie that questions the use of force. It questions what was done in the name of finding bin Laden' (cited in Winter 2013: 32). The construction of Maya suggests that Bigelow is interested in deploying 
ambiguity to prompt such questioning, but as we see from the contrasting readings cited in the previous section, what can result is a structural ambivalence that affirms rather than challenges spectators' wider convictions. ${ }^{5}$ It is possible that Bigelow's moral ambitions were overtaken by events. She and screenwriter Mark Boal originally set out to make a film about the failed attempt to apprehend Osama bin Laden in the Tora Bora mountain caves of Afghanistan in December 2001, drawing on Dalton Fury's book Kill Bin Laden: A Delta Force Commander's Account of the Hunt for the World's Most Wanted Man (2008), a focus that would have lent itself much more obviously to a thematic questioning of 'what was done in the name of finding bin Laden.' However, as the discovery and killing of bin Laden in a compound in Abbottabad, Pakistan on May 2, 2011 came to light, Bigelow and Boal decided to alter the screenplay to accommodate the new events. The resulting film's truth claim in its opening title card ('The following motion picture is based on first hand accounts of actual events') obscures the process of selection and omission that Bigelow and Boal went through to compress this new, longer timeframe into a workable feature narrative: that the 'first hand accounts' would be only from American CIA agents, keen to give a positive account of their own and their agency's involvement.

As a result, the narrative framework in which Maya's characterisation sits is less ambiguous than Bigelow might have originally intended. The film opens with a black screen and the sounds of rising panic in the voices of people calling from the World Trade Center before its collapse on September 11, 2001. This gut-wrenching invocation of terrorist-inflicted collective trauma is followed by the first 'enhanced interrogation,' notably of someone with a proven connection to those attacks, a move that seems to connect the two events in a causal chain structured around ideas of retribution and revenge, rather than a questioning of torture's efficacy. This pattern is repeated across the first half of the film, as the CIA's surveillance and interrogation activities alternate with a series of terrorist attacks in Saudi Arabia, London, Pakistan, and Afghanistan. In a rich account of the film, Robert Burgoyne has suggested that Zero Dark Thirty's 'expanding, widening loop' of violence offers a critique of the 'cycle of revenge in war' and its deleterious consequences (2014: 191-2). However, the opposite may also be true: the affective thickness of these moments, as the spectator's own embodied memories of 
their responses to specific real-world terrorist attacks converge with their sense of the implications for the fictional CIA agents they are watching, may move the spectator towards sympathy for the 'payback' principles that drive this cycle of violence. Jonathan Lighter captures the spectator's challenge well: 'You're left to form your own opinion,' he observes, 'which may be complicated by the scenes of al-Qaeda bombings and machine-gun attacks and Bigelow's prefatory, black-screen audio of wrenching phone calls from the burning Twin Towers' (2014: 6). The narrative patterning here risks producing a causal chain that exchanges moral and geopolitical complexities for reductive mythology: that there exists a 'unified Islamic fundamentalist world' (Khatib 2006: 175), and that terrorist attacks should provoke death-dealing in turn.

This narrative patterning is also structured by omissions of pertinent aspects of the historical record omissions that seem at odds with Bigelow's stated aspirations for the film, since their absence means that the reductive mythology that I have suggested is potentially readable in the narrative framing is not explicitly challenged within the film's dramatic action. For example, no mention is made of the public and political debates around the war on terror, the wars in Afghanistan or Iraq, the US drone programme, Guantanamo Bay or the prisoner abuses at Abu Ghraib. These omissions challenge the spectator's ability to see the events of the film in a wider geopolitical context, or from different points of view. If a narrow focus on counter-terrorist activities connected to the hunt for bin Laden might be presented as the motivation for such absences, a more striking omission elides the debates that were actually taking place within government agencies during the period the film covers, about the efficacy and legality of torture, debates which resulted in high profile resignations and the pulling out of FBI staff from interrogation sites. There is also no mention of the scores of detainee deaths during interrogation activities, or of the traumatic effects of torture not just on the detainees but also on the torturers themselves (McSweeney 2014: 39, 41). In this way, the opportunity to portray the felt ambivalence of either individuals or organisations about torture (a part of the extant historical record) is not taken up, and in its place, as Guy Westwell points out, 'the film's neat, chapter-like structure and the way in which the dogged, difficult work of the CIA investigation is set against a backdrop of 
repeated terrorist attacks $(\ldots)$ lends a purifying coherence to the chaos and contingency of the recent past' (2013: 86).

If the project of the film is to encourage the spectator to count the costs and consequences of violence, then it does so through a persistently American lens that produces its own erasures. The film spends the majority of its running time in the CIA's offices, screening spaces and conference rooms in the US embassy in Pakistan, as well as government corridors in the US, and the forward operating base in Afghanistan from which the attack on bin Laden was launched. This means that exterior spaces outside the US embassy in Islamabad, or in the bustling streets of Rawalpindi, or the quieter locale of Abbottabad — are also viewed from a US perspective, often from inside the 'US' spaces, or through windows, monitors, and camera and gun sights. These 'non-US' spaces are filled, in the film, with citizens who may at any moment break into violence, from the passers-by-turned-gunmen that shoot at Maya's car as she tries to leave the Islamabad office to the noisy crowd that amasses outside the Abbottabad compound during the raid. A scene featuring a demonstration against the CIA chief in Pakistan, whose identity has been revealed by the family of the victim of an American drone attack, is indicative of what this American perspective implies and elides. After some brief exterior whip pans in which the rowdy, chanting crowds fill the frame, a cut into the interior of Maya's vehicle shows Maya flinching as protestors surround and repeatedly hit the car, intercut with some glimpses through the windscreen from her point of view. Aligned spatially and narratively with Maya, the crowds are difficult for the spectator to individuate, their banners and the motivations behind them difficult to discern clearly. As Shohini Chaudhuri has noted, as "presented in the film, the demonstrators are threatening, potentially violent terrorists filled with anti-American sentiment. There is no sense that protest against the drone policy could be justified, though reports have suggested that drone strikes routinely kill substantial numbers of civilians' (2014: 31). The lived quotidian spaces and routines of non-violent civilian experience in these regions are rendered invisible, in their place a paranoid ‘imaginative geography’ (Said, 1978) of threatening perpetrators and touchpaper environments. 
The intense, detailed focus on procedures of intelligence gathering, surveillance, and detective work, 'maintains a conceit of historical neutrality' (Zimmer 2015: 210), but in fact perpetuates the negative framing of spaces and peoples identified above in the film's imaginative construction of space. Glimpsed in clipped segments from longer conversations, mediated through grainy footage from surveillance cameras or video screens, the network of detainees displayed in the interrogation videos Maya sifts through are depersonalised and de-contextualised. Their visible connections to family, community, and region are literally moved out of frame. The constrained focus of the interrogation questions (further constrained by their compilation into repetitions of key questions and answers by the film) additionally means that these detainees cannot speak the circumstances in which they have become radicalised or mis-identified as a terrorist suspect. Indeed, the film even obscures the possibility of misidentification: the detainees Maya confronts face to face are all confirmed in the film as connected to terrorist networks (even though some of them are not 'fulsome' in their replies, as she puts it), another choice that confirms the association of particular nationalities and ethnic groups with terrorism, and which also suppresses curiosity about these figures' wider contexts: their families, livelihoods, and lived experiences. If, as Steven Shaviro notes, Zero Dark Thirty is to be lauded for making the "nightmare of liberal proceduralism... visible at a time when its sheer ubiquity might otherwise leave us to take it for granted' (2013), there are signification portions of that 'nightmare' that remain resolutely out of frame, out of earshot, and out of mind.

\section{Somatic provocations, liminal moments: locating felt ambivalence}

So far in this chapter I have interrogated Zero Dark Thirty's strategy of studied ambiguity, showing how it serves a box-office-friendly structural ambivalence, ${ }^{1}$ and how it works less to promote active questioning and more to reflect the spectator's own position on the subject matter. Moreover, I have suggested that elements of the film's narrative framing move beyond this achievement of structural ambivalence to perpetuate negative and partial representations of Middle East citizens and spaces, and to erase wider geopolitical contexts and the historically documented, felt ambivalence of individuals

\footnotetext{
1 This question of the impact of the imperative to maximise audience share on filmmaking choices is one that Janet Harris returns to elsewhere in this volume.
} 
and organisations about aspects of counter-terrorist operations. In this final part of the essay, I want to argue that Bigelow's film occasionally displays traces of an opposing movement: towards a legible, felt ambivalence about the counter-terrorist activities depicted. These traces can be excavated in the formal characteristics of certain moments of transitory pause in the film, pauses whose liminality thematises the idea of ethical witnessing: one during the torture of Ammar, the others during the searching of bin Laden's compound.

I have already argued that the torture scenes are situated within a narrative oscillation between terrorist attacks and counter-terrorism measures that suppresses contextual information, confers an impression of causality, and frames the torture scenes within a logic of revenge and retaliation. The shot patterns used in the torture scenes do nothing to disrupt this framing: an absence of shots from Ammar's point of view, as well as a relative absence of his reaction shots, and a preponderance of non-verbal responses in the scripted performance, contribute to a marginalization of his subjectivity. The sensorially textured rendering of the physical degradation of Ammar might evoke pity, but when viewed alongside the dynamic physical and verbal expressivity of interrogator Dan (played by Jason Clarke) in the same shots, and heard alongside Dan's forceful invocations of Ammar's guilt and repeated rationalisations of torture ('If you lie to me I'm gonna hurt you'), it cannot in itself interrupt Ammar's dehumanised depiction (Chaudhury 2014: 30, Carruthers 2013: 51). Yet what does develop is a growing discomfort on the part of the spectator, which is rooted in the torture scenes' somatically acute register. Haptic close-ups of Ammar's sweating, bleeding, beaten-up body, and the equally uncomfortable sounds of him choking, pleading and crying out in pain, invite an intensifying somatic recognition that is sustained over long moments of screen time. The wish to withdraw from these vividly depicted sights and sounds of physical pain is strong, and it is a wish that the film purposefully declines to meet, instead offering us the nightmarishly endless cycle of Dan's performative shifts from violent insistence to sympathy and back again, his disturbingly fluid interrogator's patter contrasting with Ammar's guttural non-verbal pain responses.

\section{[insert figure 2 around here]}


In the third torture scene, there is a pause in this regularized violation of the body, as Dan leaves Ammar, stripped humiliatingly from the waist down, alone with Maya while he fetches another torture instrument. In the midst of his own mortification and suffering, Ammar appeals to Maya for help (see figure 2). In a medium shot Ammar says quietly: 'Your friend is an animal,' before a cut to Maya shows her declining to respond in a shadowy medium shot of her own. 'Please' Ammar asks, now in close-up, 'help me, please.' In a medium wide shot that gradually reveals itself to be positioned just behind Ammar's shoulder, Maya walks slowly and silently forward. Significantly, we are spatially much more closely aligned to Ammar than Maya in this sequence, and while we don't share Ammar's optical point of view, we are given full access to his emotional state through his expressive intonation and the close-ups of his face, and are brought into spatial alignment through the 'over the shoulder' camera set-up that arrives just before Maya replies. Just for a moment, then, Ammar is permitted to achieve Murray Smith's conditions for character alignment: 'spatio-temporal attachment and subjective access' (2003: 83). Moreover, as a result of the spectator's accumulated, uncomfortable experience of the preceding torture scenes, he or she is likely to be aligned, at a personal, literal level, with Ammar's keenness that the torture be stopped. As Ammar and the spectator wait for Maya to answer, the moment becomes intensely liminal, and infused with possibility: how will Maya answer? In his appeal to Maya's humanity, Ammar demands from her an ethical form of witnessing, one that recognises his subjectivity and hers: what Kelly Oliver, in her Levinasian formulation, calls 'response-ability'; in other words, the attempt to respond in ways that 'continually open and reopen the possibility of response' in others (2001: 19, see Levinas 1981).

Given the historical record that the spectator might be aware of - initial denials of certain forms of 'enhanced interrogation,' and the destruction of video recordings of interrogations to deny wider acknowledgment of controversial interrogation practices — this call to witness takes on a particular significance.

\section{[insert figure 3 around here]}

Maya, Ammar, and the spectator are caught in a liminal state, between past and future action, and between different possible responses. Does Maya's impassivity denote a felt ambivalence that means 
she might show leniency, or at the least allow Ammar to cover himself? Will his pain and humiliation (and the sights and sounds we are being subjected to as a result) be alleviated, even if just for a moment? This few seconds' pause in the cycle of violence allows the spectator to dream of a longer, more permanent pause. Yet when Maya does move forward to respond, she stops; right in the middle ground of the shot, declining the opportunity for physical proximity, for a spatial intimacy on which one might build dialogue and acknowledgement (see figure 3). Her verbalised response, the aggressively dogmatic statement, 'You can help yourself by being truthful,' the puritanical phrasing and intonation, and Chastain's rigid physical performance, emphatically shut down the possibilities of the liminal pause. The spatial arrangement of the bodies in the shot - Maya in the mid ground, Ammar and the spectator aligned in the extreme foreground - analogises Maya's refusal to meet Ammar's demand for acknowledgement, understanding, or compassion, her refusal of 'responseability' and its potential to open up intersubjective communication. She fails to move beyond 'seeing others with the objectifying gaze of a self-sufficient subject examining, subordinating, or struggling with the other,' to use Oliver's words (2001: 19). Maya's act of witnessing does not produce a transformation of her subjectivity or an understanding of the brutalized other, or, at the literal level, a stepping-back from government sanctioned brutality. But the film invites the audience to feel the absence of this trajectory, the loss of this possibility, in this liminal pause between bouts of torture. In this way, the film invites the spectator to become the ethical witness that Maya has failed to become. In E. Ann Kaplan's words, the film constructs a position for the spectator that 'enables attention to the situation, as against attention merely to... individual suffering, and this positioning thus opens the text out to larger social and political meanings' (2005: 125).

This invitation to 'attend to the situation' is, as this essay has tried to suggest, not commonplace in Zero Dark Thirty, but it returns in the final section of the film, in the depiction of the invasion of bin Laden's compound, where once again the formal strategy of the liminal pause appears. Here the pause is combined with a form of visual and dramatic redundancy: the spectator is forced to witness an action that seems to exceed what the situation requires in some way, and is forced to witness it in 
more than one shot. Crucially, this juxtaposition of pausing and redundancy centres around the act of killing.

As the Navy SEALs invade the compound and make their way through doors, down corridors, and up stairs, they kill a number of the compound occupants, some of whom are clearly shooting at or about to shoot at the soldiers, others not. At a number of points in this final portion of the film a pattern of pause and redundancy emerges. The first death of the operation occurs when Abu Ahmed al-Kuwaiti (Tushaar Mehra) shoots through a door just as the soldiers are trying to breach it. They return fire, and the shooting stops. Pushing through the door, they find the man lying on the floor. In a pause in the soldiers' forward momentum, the soldiers circle the body, assessing the situation. A close-up shows he is bloodied and unresponsive, but it is at this moment, when the spectator has been shown that he is no longer a threat, that the soldiers fire more bullets into his body, their impact documented in the same close-up that has already declared them unnecessary. The second killing occurs as the soldiers gain entry into another part of the compound. Abrar al-Kuwaiti (Noureddine Hajjoujou) is hiding behind an internal wall and raises his weapon to fire, but the SEALs have spotted him using their infrared goggles, and several fire on him, continuing to shoot as he falls forward and onto the floor, dead. His wife Bushra (Nour Alkawaja), falls upon him, screaming, and picks up his rifle — perhaps involuntarily, or to move it out of the way, or to fire it, it is not clear. The weapon means that she, too, is judged as a threat, and is shot. In a lingering point of view shot through the infrared goggles of one of the soldiers, it becomes clear that both are dead: the prone woman's eyes are open in a death stare, the man's eyes shut, but his immobility and the extent of his chest wounds evident (see figure 4). Once again redundant extra shots are fired into their bodies, captured in a cut to a gloomy medium close-up from a different position. The minimal lighting in this shot plunges the couple's heads into the shadows, stripping them of any identifying features, depersonalising them as if to underscore the transition from living tissue to dead matter, from personhood to absence.

[insert figure 4 around here] 
A pattern thus emerges: an initial flurry of activity as shots are fired, then a pause, as the soldier assesses whether the felled target is moving. A close-up shows, apparently incontrovertibly, that the person is dead, yet the soldier then fires further shots into the body. As non-specialists, it is difficult for the spectator to judge whether the extra shots are redundant in terms of military strategy, but the audience feels their redundancy in the somatic impact of watching a lifeless body momentarily reanimated by a penetrating bullet. This redundancy is most vividly displayed in the killing of Osama bin Laden (Ricky Sekhon) himself. SEALs approach a doorway, and spot movement inside the room, firing off a shot as the soundtrack conveys the thump of a body hitting the floor. As the camera moves with the soldiers into the room, bin Laden is shown lying just beyond the threshold, inert. The camera follows the soldiers as they jump across the room to subdue two screaming women, and off-screen two further shots, presumably into the body of bin Laden, are heard. While the women continue to scream in the background, a soldier twice stands over the stilled body and fires off further shots. We witness the bullet impacts — that is, the unsettling redundancy of these repeated actions — in even closer framings that we did earlier: just the shirt-clad torso, extant bullet holes clearly visible. The pattern of pause and redundancy gains force through the spectator's accumulated experience of the compound scenes, as well as through the specificities of the depiction of each moment; in each case the pause, motivated by the soldier's need to complete a threat assessment, is a liminal moment between shooting and not shooting, more or less bullet holes, a more or less intact body; in each case (after the first) the possibility of not shooting again is thrown into relief by the next redundant bullet, the sense of the waste of this war on terror compounded with each extra unnecessary pull of the trigger. Moreover, the unnecessary bullet impacts are themselves captured in closer and closer views, as if the film wants to press the point home through unasked-for and repeated proximity to the haptic textures of the breached, dead body.

It is in these moments of pause, between stillness and action, that the film's felt ambivalence comes productively to the surface, pushing beyond the wider tendency towards inert ambiguity, to depictions that promote and demand reflection on what is possible, as well as what was done. Interrupting Zero Dark Thirty's structural ambivalence, and its hermetic diegesis that elides non-American perspectives, 
geopolitical contexts, and so much of the historical record, these moments can perhaps be seen as the trace of Bigelow's original ambitions for the film. In Zero Dark Thirty's landscape of erasure, absence, and ambiguity, these are the presences that complicate, that problematise, that demand thought and reflection on this most complex of stories. Yet their force is blunted by the contexts in which they sit: the film itself, and beyond it a world powerfully shaped by ideologically loaded and heavily politicised rhetorical oppositions between 'us' and 'them,' and a US film industry equally powerfully shaped by economic imperatives that compel filmmakers to prioritise maximising audiences over overt political complexity.

As this essay has shown, the film constructs a causal chain that begins with the $9 / 11$ atrocities and ends with the capture and death of their architect, a choice that provides a genre-familiar revenge trajectory and a forceful narrative closure, even as the final shot of the film (of Maya in the plane) tries to work against these elements. ${ }^{6}$ Restating the juxtaposition between frame and moment that has characterised much of my analysis in this essay permits reflection on the challenge that Zero Dark Thirty faces, and the ways in which it fails this challenge. A narrative framing whose shape is familiar from public and political discourse, as well as from film genre conventions, exerts a gravitational force that pulls the spectator away from attending to the nuances of the strategies that Bigelow's moral project seemed to put in play. In his positive account of the film, Michael Boughn notes that art should raise 'questions that propel the mind not toward answers but toward questions' (19), but this essay has argued that the partisan 'answers' supplied by Zero Dark Thirty's narrative frame speak more loudly and more consistently than the moments that seek to invite a questioning response. Such analysis raises a wider question for ethically minded cultural producers: is there any longer a place for ambiguity and ambivalence? The lesson provided by Zero Dark Thirty's conflicted form might well be that, at a cultural moment filled with the heat and noise of polarised and polarising post-9/11 geopolitics, and in a cultural product designed for the lay spectator, the invitation to ask questions must surely be posed as forcefully as the many 'answers' that noisily circulate in public, media and political discourse. 


\section{Notes}

${ }^{1}$ Tomasulo was discussing Apocalypse Now (Francis Ford Coppola, 1979).

${ }^{2}$ Indeed Robert Burgoyne suggests that the final shot makes explicit a 'theme of suspension' that has characterised the earlier scene of Osama bin Laden in the body bag: 'This devastating scene undercuts any sense of triumph or blood satisfaction... In some ways we are suspended here, without resolution, without the climax that the film has prepared from the beginning' (2014: 197).

${ }^{3}$ Susan Carruthers concurs with Chaudhuri's reading, arguing that 'Zero Dark Thirty may not "glorify" torture, as Greenwald charged, but its shit-smeared verisimilitude directs disgust more toward the victim than the perpetrator' (2013: 51).

${ }^{4}$ Here I am referring to the 'Kuleshov effect,' which offers an interesting perspective on Maya's performance and responses to it. The term derives from V. I. Pudovkin's famous but perhaps apocryphal 1929 account of fellow Russian filmmaker Kuleshov's montage experiment:

'Kuleshov and I made an interesting experiment. We took from some film or other several close-ups of the well-known Russian actor Mosjukhin. We chose close-ups which were static and which did not express any feeling at all - quiet close-ups. We joined these close-ups, which were all similar, with other bits of film in three different combinations. In the first combination the close-up of Mosjukhin was immediately followed by a shot of a plate of soup standing on a table. It was obvious and certain that Mosjukhin was looking at this soup. In the second combination the face of Mosjukhin was joined to shots showing a coffin in which lay a dead woman. In the third the close-up was followed by a shot of a little girl playing with afunny toy bear. We we showed the three combinations to an audience which had not been let into the secret the resul was terrific. The public raved about the acting of the artist. They pointed out the heavy pensiveness of his mood over the forgotten soup, were touched and moved by the deep sorrow with which he looked on the dead woman, and admired the light, happy smile with which he surveyed the girl at play. But we knew that in all three cases the face was exactly the same.' (Pudovkin 1929, cited in Holland 1992: 79-80). 


\footnotetext{
${ }^{5}$ Screenwriter Mark Boal seems to equate structural ambivalence with the success of his and Bigelow's moral project: that is, the inclusion of scenes in which torture seems to work, and scenes in which it doesn't prove valuable. For Steve Coll, these kinds of 'on-the-one hand, on-the-other forms of argument about the value of officially sanctioned torture represents a victory for those who would justify such abuse' (2013).

${ }^{6}$ The narrative trajectory of revenge and retribution is one that spectators familiar with Hollywood genre films (such as Westerns, action movies, detective thrillers, and so on) will readily recognise.
}

\section{Bibliography}

Bigelow, K. (2013), 'Kathryn Bigelow addresses Zero Dark Thirty torture criticism', LA Times, 15 January. Available at <http://articles.latimes.com/2013/jan/15/entertainment/la-et-mn-0116-bigelowzero-dark-thirty-20130116> (last accessed 1 May 2016).

Boughn, M. (2013), 'The War on Art and Zero Dark Thirty', CineACTION 91, pp. 19-26.

Burgoyne, R. (2014), 'The Violated Body: Affective Experience and Somatic Intensity in Zero Dark Thirty', in David LaRocca (ed), The Philosophy of War Films, Lexington, Kentucky: University Press of Kentucky, pp. 189-98.

Carruthers, S. (2013), 'Zero Dark Thirty', Cineaste. Spring, pp. 50-52.

Chaudhury, S. (2014), Cinema of the Dark Side: Atrocity and the Ethics of Spectatorship, Edinburgh: Edinburgh University Press.

Coll, S. (2013), 'Disturbing and Misleading', New York Review of Books, 7 February. Available at <http://www.nybooks.com/articles/2013/02/07/disturbing-misleading-zero-dark-thirty/> (last accessed 
1 May 2016).

Debruge, P. (2012), 'Review: Zero Dark Thirty,' Variety, 25 November. Available at <http://variety.com/2012/film/reviews/zero-dark-thirty-1117948801/> (last accessed 1 May 2016).

Holland, N. N. (1992), 'Film Response from Eye to I: The Kuleshov Experiment', in J. Gaines (ed.), Classical Hollywood Narrative: The Paradigm Wars, London: Duke University Press, pp. 79-106.

Hornaday, A. (2012), 'Zero Dark Thirty and the new reality of reported filmmaking', The Washington Post, 13 December. Available at <https://www.washingtonpost.com/entertainment/movies/zero-darkthirty-and-the-new-reality-of-reported-filmmaking/2012/12/13/3630ce2c-4548-11e2-8e70e1993528222d_story.html> (last accessed 1 May 2016).

James, N. (2013), 'Zero Tolerance (Editorial)', Sight and Sound, February, p. 9.

Kaplan, E. A. (2005), 'The Ethics of Witnessing: Maya Deren and Tracey Moffatt', in E. A. Kaplan (ed.), Trauma Culture: The Politics of Terror and Loss in Media and Literature. Piscataway, NJ: Rutgers University Press, pp. 122-135.

Khatib, L. (2006), Filming the Modern Middle East: Politics in the Cinemas of Hollywood and the Arab World, London: I.B. Taurus.

Levinas, E. (1981), trans. Alphonso Lingus, Otherwise than Being or Beyond Essence, The Hague: Martinus Nijhoff.

Lighter, J. (2014), 'Zero Dark Thirty: A Review', War, Literature \& the Arts 26: pp. 4-6 
Maas, P. (2012), 'Don't Trust Zero Dark Thirty', The Atlantic, 13 December. Available at <http://www.theatlantic.com/entertainment/archive/2012/12/dont-trust-zero-dark-thirty/266253/> (last accessed 1 May 2016).

Maltby, R. (2003), Hollywood Cinema, $2^{\text {nd }}$ edn, Oxford: Blackwell Publishing.

McSweeney, T. (2014), The 'War on Terror' and American Film: 9/11 Frames Per Second, Edinburgh: Edinburgh University Press.

Piotrowska, A. (2014), 'Zero Dark Thirty - “war autism” or a Lacanian ethical act?' New Review of Film and Television Studies, 12.2, pp. 143-55.

Said, E. (2003), Orientalism, London: Penguin Books.

Shaviro, S. (2013), ‘A Brief Remark on Zero Dark Thirty', The Pinocchio Theory, 18 January. Available at <http://www.shaviro.com/Blog/?p=1114\&num;comments> (last accessed 1 May 2016).

Tomasulo, F. P. (1990), 'The Politics of Ambivalence: Apocalypse Now as Pro-war and Anti-war Film', in L. Dittmar and G. Michaud (eds), From Hanoi to Hollywood: the Vietnam War in American Film, New Brunswick, Rutgers University Press, pp. 145-58.

Westwell, G. (2013), 'Zero Dark Thirty', Sight and Sound (February), pp. 86-7.

Westwell, G (2014), Parallel Lines: Post-9/11 American Cinema, London: Wallflower Press.

Winter, J. (2013), 'Kathryn Bigelow: The art of darkness', Time, 181: 4 (February 4), pp. 30-7.

Wolf, N. (2013), 'A letter to Kathryn Bigelow on Zero Dark Thirty's apology for torture', The Guardian, 4 January. Available at <http://www.theguardian.com/commentisfree/2013/jan/04/letter- 
kathryn-bigelow-zero-dark-thirty> (last accessed 1 May 2016).

Zimmer, C. (2015), Surveillance Cinema, New York: New York University Press.

Zizek, S. (2013), 'Zero Dark Thirty: Hollywood's gift to American power', The Guardian (January 25). Available at <http://www.theguardian.com/commentisfree/2013/jan/25/zero-dark-thirtynormalises-torture-unjustifiable> (last accessed 1 May 2016). 